\title{
Treatment of Type A dissection: searching for the Holy Grail.
}

Domenico Calcaterra $^{1}$

${ }^{1}$ Florida Atlantic University

February 16, 2021

\begin{abstract}
Surgical treatment of type A dissections is based on best evidence practice for the lack of controlled randomized studies providing definitive scientific evidence. Despite its widespread use, axillary cannulation still remains a debated topic as the preferred method of cannulation and perfusion strategy in the treatment of this complex condition.
\end{abstract}

\section{Hosted file}

EditorialJOCSPochettinoFinal.pdf available at https://authorea.com/users/396128/articles/ 509280-treatment-of-type-a-dissection-searching-for-the-holy-grail 


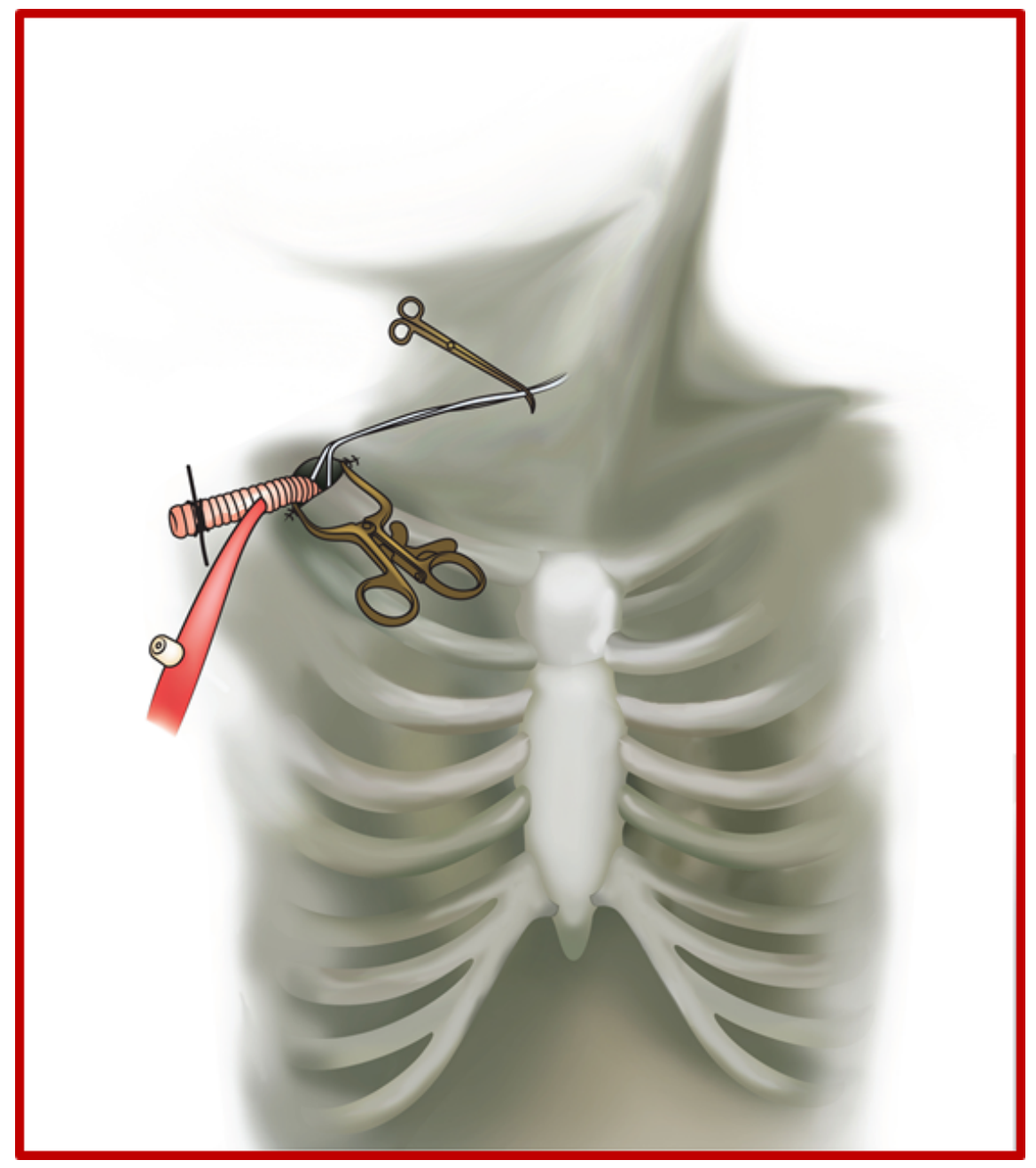

